\title{
A multi-strain Synbiotic may reduce viral respiratory infections in asthmatic children: a randomized controlled trial
}

Hamid Ahanchian ${ }^{1,2}$, Seyed Ali Jafari ${ }^{3}$, Elham Ansari ${ }^{4}$, Toktam Ganji ${ }^{5}$, Mohammad Ali Kiani ${ }^{3}$, Maryam Khalesi ${ }^{5}$, Tooba Momen ${ }^{6}$, Hamidreza Kianifar ${ }^{3}$

1 MD, Children's Health and Environment Program, Queensland Children's Medical Research Center, The University of Queensland, Brisbane, Australia

${ }^{2}$ MD. Allergist and Immunologist, Associate Professor, Department of Pediatrics , Faculty of Medicine, Mashhad University of Medical Sciences, Mashhad, Iran

${ }^{3}$ MD. Pediatric gastroenterologist, Associate Professor, Department of Pediatrics, Faculty of Medicine, Mashhad University of Medical Sciences, Mashhad, Iran

${ }^{4}$ MD. Radiologist, Department of Pediatrics, Faculty of Medicine, Mashhad University of Medical Sciences, Mashhad, Iran

${ }^{5}$ MD. Pediatrician, Department of Pediatrics, Faculty of Medicine, Mashhad University of Medical Sciences, Mashhad, Iran

${ }^{6}$ MD. Division of Allergy and Clinical Immunology, Research institute for Primordial Prevention of Noncommunicable Diseases, Isfahan University of Medical Sciences, Isfahan, Iran

Type of article: Original

\begin{abstract}
Background and objective: Asthma is a growing problem worldwide. Acute exacerbations impose considerable morbidity, mortality, and increased cost. Viral respiratory infections are the most common cause $(80-85 \%)$ of pediatric asthma exacerbations and admissions to the hospital. The aim of this study was to determine the effect of a new synbiotic Lactocare ${ }^{\circledR}$ on viral respiratory infections and asthma exacerbations in asthmatic children.

Methods: In this double blind, placebo-controlled, randomized clinical trial, 72 children with mild persistent

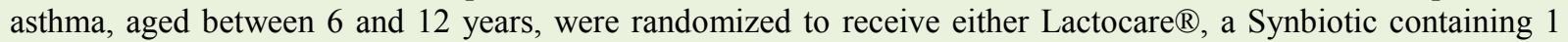
billion CFU/Capsule of Lactobacillus casei, Lactobacillus rhamnosus, Streptococcus thermophilus, Bifidobacterium breve, Lactobacillus acidophilus, Bifidobacterium infantis, Lactobacillus bulgaricus, and Fructooligosacharide (Zist Takhmir, Tehran, Iran) or placebo daily for 60 days. The primary outcome was the number of viral respiratory infections, and secondary outcomes were school absence, salbutamol and prednisolone usage, outpatient visits, and hospital admission for asthma. The outcomes were compared among study groups using the SPSS 11.5 program and the Mann Whitney and Fisher exact tests.

Results: Of the 72 children who were enrolled with mild persistent asthma, 36 were assigned randomly to be treated with synbiotic and 36 with placebo. The number of viral respiratory infections was significantly higher in placebo group than the synbiotic group during the first month of intervention $(0.74 \pm 0.12$ vs. $0.44 \pm 0.1$, p $<$ $0.007)$ but not during the second month $(0.5 \pm 0.8$ vs. $0.5 \pm 0.8, p<0.641)$. Considering the total duration of the study (two months), infection episodes also were significantly lower in the synbiotic group (0.92 \pm 0.15 vs. 0.69 $\pm 0.11, \mathrm{p}<0.046)$. Salbutamol consumption was significantly lower in the synbiotic group, but there were no significant differences in school absenteeism, oral prednisolone use, outpatient visits, or hospital admissions.

Conclusion: This new synbiotic (a mixture of seven probiotic strains plus fructooligosacharide may reduce episodes of viral infection in asthmatic children.

Trial registration: This study is registered in Iranian Registry of Clinical Trials with registration number of IRCT201509234976N3.

Funding: This research was supported financially by the Research Council of Mashhad University of Medical Sciences (Grant Number: 911048).

Keywords: Asthma, Children, Probiotic, Synbiotic, Viral infection, Asthma exacerbation

\section{Corresponding author:}

Associate Professor Dr. Hamidreza Kianifar, Department of Pediatrics, Faculty of Medicine, Mashhad University of Medical Sciences, Mashhad, Iran. Tel: +98.5138012469, Fax: +98.5138417451, E-mail: Kianifarhr@mums.ac.ir Received: January 22, 2016, Accepted: May 03, 2016, Published: September 2016 iThenticate screening: April 18, 2016, English editing: July 24, 2016, Quality control: August 04, 2016

(C) 2016 The Authors. This is an open access article under the terms of the Creative Commons Attribution-NonCommercialNoDerivs License, which permits use and distribution in any medium, provided the original work is properly cited, the use is non-commercial and no modifications or adaptations are made.
\end{abstract}




\section{Introduction}

Asthma is an increasing problem worldwide. It is the most common chronic disease of childhood, and it is a common cause of childhood morbidity, including school absences, emergency visits, and hospitalizations (1). The acute exacerbations that continue to occur constitute a major burden on health care resources and have been associated with decreased lung growth $(2,3)$. Viral respiratory infections are the most common cause $(80-85 \%)$ of pediatric asthma exacerbations and admissions to the hospital (4). Recent studies have shown that the airway's epithelial cells in asthmatics can produce less anti-viral inteferons IFN- $\beta$ and IFN- $\lambda$ when infected with Human Rhinoviruses (HRVs), making them potentially more susceptible to viral infections (5). Current medications for the prevention of virus-induced exacerbation of asthma's symptoms are not effective, and novel therapies should be sought (6). Hand hygiene techniques, a balanced diet, probiotics, and the immunostimulant OM-85 are considered to be the most effective methods for preventing the common cold in asthmatic children (6). Many clinical trials have used probiotics for the prevention of the common cold in healthy children and adults with promising results (7-14). Synbiotics, defined as a combination of a probiotic and a prebiotic, the aim of which is to increase the survival and activity of probiotics, can reduce respiratory viral infection by modulation of the Th1/Th2 responses in the lungs (15-17). Some studies have shown that synbiotics may reduce the duration of viral infections in healthy school children and reduce Th2 cytokine in asthmatic children $(18,19)$. The aim of this study was to determine efficacy of synbiotic Lactocare ${ }^{\circledR}$, a mixture of seven probiotic strains plus fructooligosacharide (FOS) in reducing seasonal viral upper respiratory infection in asthmatic children.

\section{Material and Methods}

\subsection{Research design and setting}

This double-blind, placebo-controlled, randomized clinical trial was conducted at Sarvar Teaching Hospital in Mashhad, Iran, with the sample population recruited from the outpatient pediatric allergy clinic from September 2012 to September 2014.

\subsection{Participants}

Children in the age range of 6 to 12 years with mild persistent asthma and a history of recurrence (at least two viral upper respiratory infections in past autumn) were enrolled. We excluded those with with congenital abnormalities or syndromes, antibiotic or probiotic consumption during the two weeks before the study, and any underlying disease. During the first visit, demographic information was collected, including gender, age, birth weight, antibiotic consumption, family history of allergies, exposure to allergens and irritants, history of recurrent infection, and severity of asthma.

\subsection{Sample size}

According to previous studies that showed a $20-30 \%$ reduction (14) in common colds with a probiotic, we estimated a sample size of 35 in each group using an $\alpha$ value of 0.05 with a power of $90 \%$ and possible $20 \%$ follow-up loss. $\mathrm{N}$ $=7.8\left(\mathrm{~S}_{1}{ }^{2}+\mathrm{S}_{2}{ }^{2}\right) /\left(\mathrm{M}_{2}-\mathrm{M}_{1}\right)^{2}=28.38$

\subsection{Randomization}

Computer-generated randomization was conducted by a university statistician.

\subsection{Blinding}

In this double-blinded study, the treatment plan of each group was prepared by the hospital pharmacist and delivered to the investigator. The patient was not aware of the type of solution that was being used. Interventions were concealed from the study's investigators, the pharmacist, and the parents to minimize treatment bias.

\subsection{Interventions}

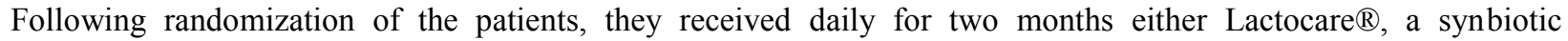
containing 1 billion CFU/Capsule of Lactobacillus casei, Lactobacillus rhamnosus, Streptococcus thermophilus, Bifidobacterium breve, Lactobacillus acidophilus, Bifidobacterium infantis, Lactobacillus bulgaricus, and Fructooligosacharide (Zist Takhmir, Tehran, Iran) or a placebo that was matched with the color, size, and shape of the medication. Before enrolment in the study, an education session was conducted focusing on recommended hygienic measures, including frequent hand washing, use of disposable tissues, having sick family members wear a face mask and keep a distance of a meter away from the patient, and avoiding any kind of smoking. Patients were assessed by a single physician at enrolment, at the end of the first month, at the end of second month, and every time they had respiratory tract symptoms when a viral respiratory infection was suspected. A complete history of any new 
symptom, drug usage (salbutamol, prednisolone), school absenteeism, outpatient visits, and hospital admission was taken, and physical examinations were done to rule out any presumed new signs, such as wheezing, otitis media, and pneumonia.

\subsection{Outcomes}

The total number of respiratory viral infection episodes over two months of follow-up was considered as the primary outcome. Acute viral upper respiratory tract infection episodes (acute nasopharyngitis or common cold) were diagnosed clinically by a single pediatrician in the presence of diagnostic symptoms (fever, sneezing, cough, rhinorhea, and sore throat) that lasted at least 48 hours. Multiple episodes were counted only if the patient was without symptoms for at least 72 hours between episodes. School absenteeism, salbutamol usage, prednisolone usage, outpatient visits, and hospital admissions were considered as secondary outcomes.

\subsection{Research ethics}

The protocol for this study was approved by Ethics Committee of Mashhad University of Medical Sciences.

\subsection{Statistical methods}

The SPSS 11.5 program (SPSS, Inc., Chicago, IL, USA) was used to perform statistical analysis. For normally distributed variables, values were reported as mean $\pm \mathrm{SD}$. The t-test, chi-squared test, and/or the Fisher exact test were used as appropriate to compare baseline demographics and the clinical characteristics among the study groups. Normality was assessed using the 'Kolmogorov-Smirnov' test.

\section{Results}

\subsection{Baseline characteristics}

Of the 75 children enrolled with mild, persistent asthma, 37 were assigned randomly to be treated with Synbiotic and 38 with placebo. One patient in the synbiotic group was excluded from the analysis due to non-compliance and two patients in placebo group were excluded for the following reasons: lost to follow up $(\mathrm{n}=1)$ and abdominal pain $(n=1)$. Seventy-two children completed the study, 36 patients in each groups (Figure 1). There were no significant differences in baseline characteristics between the synbiotic and placebo groups (Table 1).

\subsection{Viral respiratory infection}

There was a significant difference for the number of viral respiratory infections between the intervention and placebo groups during the first month of treatment $(\mathrm{p}<0.007)$; this was not the case during the second month $(\mathrm{p}<$ 0.641) (Table 2). Considering the total duration of the study (two months), infection episodes also were significantly lower in the synbiotic group $(\mathrm{p}<0.046)$.

\subsection{Salbutamol consumption}

Salbutamol consumption was significantly lower in the synbiotic group than in the placebo group (p $<0.017$ ), but there were no significant differences between the two groups in school absenteeism oral prednisolone, outpatient visits, or hospital admissions (Table 3).

\subsection{Side effects}

There were no side effects in either group.

Table 1. Baseline characteristics of the study's participants

\begin{tabular}{|l|l|l|l|}
\hline Variables, unit & Placebo Group $(\mathrm{n}=36)$ & Synbiotic Group $(\mathrm{n}=36)$ & $\mathrm{p}$-value \\
\hline Gender (Male/Female) & $23 / 13$ & $22 / 14$ & $0.808^{*}$ \\
\hline Mean age (first visit), year & $8.2 \pm 2.1$ & $8.1 \pm 1.7$ & $0.819^{* *}$ \\
\hline Positive family history of allergies, number & 15 & 13 & $0.893^{*}$ \\
\hline School attendance, $\mathrm{n}$ & 36 & 36 & $0.999^{*}$ \\
\hline Household smoke exposure, number & 7 & 6 & $0.927^{*}$ \\
\hline
\end{tabular}

*:Chi-square test, ** Mann-Whitney test 
http://www.ephysician.ir

Table 2. Primary outcome between study groups during the first and second month of treatment

\begin{tabular}{|l|l|l|l|}
\hline Primary outcome (Infection episodes) & Synbiotic group $(\mathrm{n}=36)$ & Placebo group $(\mathrm{n}=36)$ & $\mathrm{p}$-value* \\
\hline First month, mean \pm SD & $0.44 \pm 0.1$ & $0.74 \pm 0.12$ & 0.007 \\
\hline Second month, mean \pm SD & $0.5 \pm 0.8$ & $0.5 \pm 0.8$ & 0.641 \\
\hline Total, mean \pm SD & $0.69 \pm 0.11$ & $0.92 \pm 0.15$ & 0.046 \\
\hline
\end{tabular}

*Mann-Whitney test

Table 3. Secondary outcome measures between study groups during two months of treatment

\begin{tabular}{|l|l|l|l|}
\hline Secondary outcomes & Synbiotic group $(\mathrm{n}=36)$ & Placebo group $(\mathrm{n}=36)$ & $\mathrm{p}$-value* \\
\hline Salbutamol usage, $\mathrm{n}$ & 16 & 26 & 0.017 \\
\hline Oral Prednisolone, $\mathrm{n}$ & 1 & 3 & 0.303 \\
\hline Outpatient visits, $\mathrm{n}$ & 14 & 21 & 0.099 \\
\hline School absent, $\mathrm{n}$ & 7 & 9 & 0.571 \\
\hline Hospital admission, $\mathrm{n}$ & 0 & 1 & 0.314 \\
\hline
\end{tabular}

*: Fisher's exact test

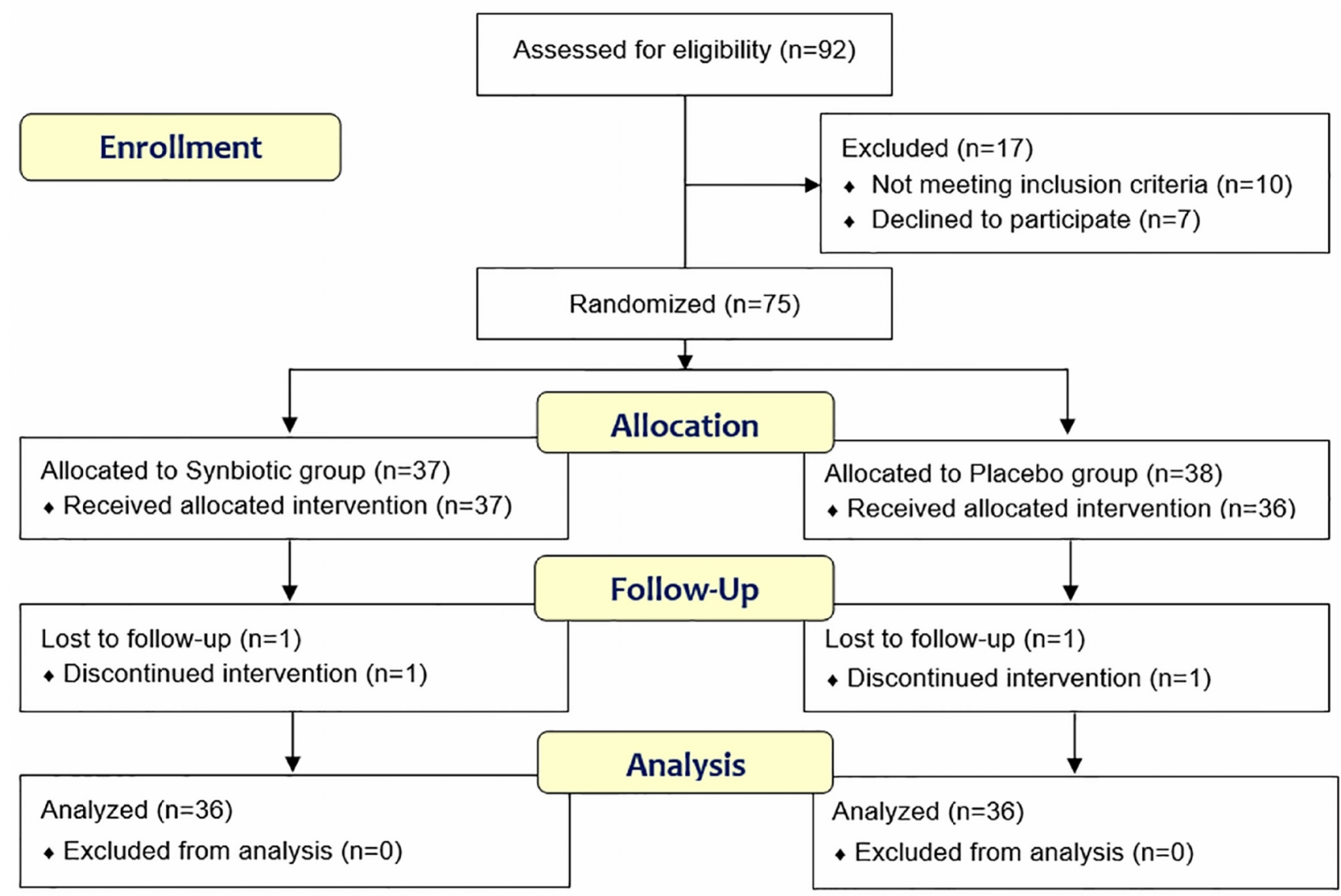

Figure 1. Follow-up diagram of patients (according to consort statement)

\section{Discussion}

In the present study, a synbiotic containing a mixture of seven probiotic strains and the prebiotic fructooligosacharide was associated with fewer episodes of viral respiratory infection in children with mild persistent asthma. These results are promising as the common cold occurs each fall and winter, and current drugs for the prevention of virus-induced exacerbation of asthma are not very effective. In this study, we focused on patients with a history of recurrent infection in the previous season, as among inner-city children with asthma. A history of exacerbation in the previous season is the strongest predictor of asthma exacerbation in fall and winter (20). Several studies of healthy children and adults have shown the benefits of probiotics in respiratory infections. In 2015 , a Cochrane review written by Hao et al. concluded that probiotics were better than placebo in reducing the number of participants who experienced episodes of acute upper respiratory infection, reducing the mean duration of an 
episode, reducing the use of antibiotics, and reducing cold-related absences from school (14). The therapeutic role of probiotics in asthma has been tested in a few clinical trials considering various outcomes and study designs. The earlier studies failed to show any significant benefits. In 1997, Wheeler concluded that yogurt that contained L. acidophilus produced borderline elevated interferon gamma levels in asthmatic adults, but it did not improve lung function or quality of life (21). In 2007, Giovannini et al. showed that consuming fermented milk containing a Lactobacillus casei over a 12-month period did not change the episodes of fever or diarrhea in asthmatic children whose ages ranged from two to five (22). These results may be explained by the fact that the effects of probiotics depend on dose, duration, and the strains used in trials, and only specific strains with accurate dose can reduce the episodes of upper respiratory infections. Some researchers confirmed the benefits of probiotics by using different study protocols. In Poland, Gutkowski and colleagues evaluated the effects of the treatment of asthmatic children with a 12-week regimen of Trilac capsules, which contained a mixture of Lactobacillus acidophilus, Bifidobacterium bifidum, and Lactobacillus delbrueckii subsp. Bulgaricus (23). Trilac significantly improved lung function and reduced episodes of asthma exacerbations. Previous studies have shown that a mixture of multiple probiotic strains might be more effective than a single strain, although the components of the mixture should be chosen carefully based on their proven efficacy for treating that special disease, because the efficacy of the mixtures may be decreased by any inhibitory effects that exist between the different probiotic strains (24). We used a mixture of seven probiotic strains plus the prebiotic fructooligosacharide (FOS). Many of these strains have proven efficacy in reducing viral respiratory infections. The prebiotic in the symbiotic mixture improved the survival of the probiotics and the host endogenous good bacteria, and it also stimulated induction of regulatory $\mathrm{T}$ lymphocytes and immune tolerance. In 2011, Van de Pol et al. showed that treatment with synbiotics (short-chain galactooligosaccharides, long-chain fructo-oligosaccharide and Bifidobacterium breve) in adults with allergic asthma significantly reduced the production of Th2-cytokines after allergen challenge and improved peak expiratory flow rates (19). In 2013, a systematic review of the effects of probiotics in allergic airway diseases was conducted by Dos et al. and they concluded that probiotics did not improve quality of life scores in asthmatics but could improve the following parameters, i.e., longer time free from episodes of asthma and decrease in the number of episodes of rhinitis per year. They also concluded that routine use of probiotics as an additive therapy in subjects with allergic airway diseases should not be recommended (25). Our study also showed the effects of synbiotics on reduction of number of viral respiratory episodes in asthmatic children. In another study in Austria, Stocker and colleagues concluded that in asthmatic children in the age range of 6 to 12, laser acupuncture for 10 weeks plus probiotic Enterococcus faecalis for seven weeks had fewer days of acute febrile infections than the control group (26).

In our study, although prednisolone usage, outpatient visits, school absences, and hospital admissions were lower in the synbiotic group, the difference was not statistically significant. This was the same as the results of another study in which Lactobacillus rhamnosus (ATCC 53103) made no significant change in asthma medications during Birch pollen season (27). In fact, some strains of probiotics may even worsen the asthma-like symptom and increase the need for rescue medication (28). An extensively hydrolyzed formula with Bifidobacterium breve $\mathrm{M}-16 \mathrm{~V}$ and a galacto / fructooligosaccharide mixture prevents asthma-like symptoms, including 'frequent wheezing' and 'wheezing and/or noisy breathing' in infants with atopic dermatitis (29). These different results emphasize the importance of accurately selecting the proper probiotic strain in treating allergic disorders. In our study, the use of synbiotics significantly reduced Salbutamol usage during the period of viral respiratory infections. One other study also showed that probiotics may reduce bronchodilator usage in asthmatic patients (23). The advantages of our study were the use of a new synbiotic that contained seven probiotics, the study population (children), and careful followup of the patients several times during the study. The limitations of this study were that we did not perform pulmonary function tests or laboratory evaluation of immunologic effects.

\section{Conclusions}

A synbiotic that contains a mixture of seven probiotic strains plus fructooligosacharide may reduce episodes of viral respiratory infection in asthmatic children. For clear recommendations, well-designed RCTs with longer follow-up, larger sample sizes, and different probiotic mixtures are needed to determine the ideal, effective product, dosage, and duration for asthmatic patients.

\section{Acknowledgments:}

This manuscript was derived from a Paediatric thesis by Dr. Toktam Ganji, and the research was supported financially by the Vice Chancellor for Research, Mashhad University of Medical Sciences. The authors wish to acknowledge Professor Peter Sly from The University of Queensland for his scientific support and reviewing the manuscript. 
http://www.ephysician.ir

\section{Trial registration:}

This study is registered in the Iranian Registry of Clinical Trials with registration number IRCT201509234976N3

\section{Funding:}

This research was supported financially by the Research Council of Mashhad University of Medical Sciences (Grant number: 911048). The authors received no financial support for the authorship and/or publication of this article.

\section{Conflict of Interest:}

There is no conflict of interest to be declared.

\section{Authors' contributions:}

All authors contributed to this project and article equally. All authors read and approved the final manuscript.

\section{References:}

1) Jackson DJ, Sykes A, Mallia P, Johnston SL. Asthma exacerbations: origin, effect, and prevention. J Allergy Clin Immunol. 2011; 128(6): 1165-74. doi: 10.1016/j.jaci.2011.10.024. PMID: 22133317.

2) Sears MR, Johnston NW. Understanding the September asthma epidemic. J Allergy Clin Immunol. 2007; 120(3): 526-9. PMID: 17658590.

3) Busse WW, Lemanske RF Jr, Gern JE. Role of viral respiratory infections in asthma and asthma exacerbations. Lancet. 2010; 376(9743): 826-34. doi: 10.1016/S0140-6736(10)61380-3. PMID: 20816549, PMCID: PMC2972660.

4) Gern JE. The ABCs of rhinoviruses, wheezing, and asthma. J Virol. 2010; 84(15): 7418-26. doi: 10.1128/JVI.02290-09. PMID: 20375160, PMCID: PMC2897627.

5) Wark PA, Johnston SL, Bucchieri F, Powell R, Puddicombe S, Laza Stanca V, et al. Asthmatic bronchial epithelial cells have a deficient innate immune response to infection with rhinovirus. J Exp Med. 2005; 201(6): 937-47. PMID: 15781584, PMCID: PMC2213100.

6) Ahanchian H, Jones CM, Chen YS, Sly PD. Respiratory viral infections in children with asthma: do they matter and can we prevent them? BMC Pediatr. 2012; 12: 147. doi: 10.1186/1471-2431-12-147. PMID: 22974166, PMCID: 3471019.

7) Razi CH, Harmanci K, Abaci A, Ozdemir O, Hizli S, Renda R, et al. The immunostimulant OM-85 BV prevents wheezing attacks in preschool children. J Allergy Clin Immunol. 2010; 126(4): 763-9. doi: 10.1016/j.jaci.2010.07.038. PMID: 20920766.

8) Hatakka K, Blomgren K, Pohjavuori S, Kaijalainen T, Poussa T, Leinonen M, et al. Treatment of acute otitis media with probiotics in otitis-prone children-a double-blind, placebo-controlled randomised study. Clin Nutr. 2007; 26(3): 314-21. PMID: 17353072.

9) Hatakka K, Savilahti E, Ponka A, Meurman JH, Poussa T, Nase L, et al. Effect of long term consumption of probiotic milk on infections in children attending day care centres: double blind, randomised trial. BMJ. 2001; 322(7298): 1327. PMID: 11387176, PMCID: PMC32161.

10) Lin JS, Chiu YH, Lin NT, Chu CH, Huang KC, Liao KW, et al. Different effects of probiotic species/strains on infections in preschool children: A double-blind, randomized, controlled study. Vaccine. 2009; 27(7): 1073-9. doi: 10.1016/j.vaccine.2008.11.114. PMID: 19114073.

11) Liu S, Hu P, Du X, Zhou T, Pei X. Lactobacillus rhamnosus GG supplementation for preventing respiratory infections in children: a meta-analysis of randomized, placebo-controlled trials. Indian Pediatr. 2013; 50(4): 377-81. PMID: 23665598.

12) Niittynen L, Pitkaranta A, Korpela R. Probiotics and otitis media in children. Int J Pediatr Otorhinolaryngol. 2012; 76(4): 465-70. doi: 10.1016/j.ijporl.2012.01.011. PMID: 22305688.

13) Weizman Z, Asli G, Alsheikh A. Effect of a probiotic infant formula on infections in child care centers: comparison of two probiotic agents. Pediatrics. 2005; 115(1): 5-9. PMID: 15629974.

14) Hao $\mathrm{Q}$, Dong $\mathrm{BR}, \mathrm{Wu} \mathrm{T}$. Probiotics for preventing acute upper respiratory tract infections. Cochrane Database Syst Rev. 2015; 2: 006895. doi: 10.1002/14651858. PMID: 25927096.

15) Schijf MA, Kruijsen D, Bastiaans J, Coenjaerts FE, Garssen J, van Bleek GM, et al. Specific dietary oligosaccharides increase Th1 responses in a mouse respiratory syncytial virus infection model. J Virol. 2012; 86(21): 11472-82. doi: 10.1128/JVI.06708-11. PMID: 22896622 , PMCID: PMC3486291.

16) Farid R, Ahanchian H, Jabbari F, Moghiman T. Effect of a new synbiotic mixture on atopic dermatitis in children: a randomized-controlled trial. Iran J Pediatr. 2011; 21(2): 225-30. PMID: 23056792, PMCID: PMC3446166. 
17) Kianifar H, Ahanchian H, Grover Z, Jafari S, Noorbakhsh Z, Khakshour A, et al. Synbiotic in the management of infantile colic: A randomised controlled trial. J Paediatr Child Health. 2014; 50(10): 801-5. doi: 10.1111/jpc.12640. PMID: 24962875.

18) Kukkonen K, Savilahti E, Haahtela T, Juntunen Backman K, Korpela R, Poussa T, et al. Long-term safety and impact on infection rates of postnatal probiotic and prebiotic (synbiotic) treatment: randomized, double-blind, placebo-controlled trial. Pediatrics. 2008; 122(1): 8-12. doi: 10.1542/peds.2007-1192. PMID: 18595980.

19) van de Pol MA, Lutter R, Smids BS, Weersink EJ, van der Zee JS. Synbiotics reduce allergen-induced Thelper 2 response and improve peak expiratory flow in allergic asthmatics. Allergy. 2011; 66(1): 39-47. doi: 10.1111/j.1398-9995.2010.02454. PMID: 20716319.

20) Teach SJ, Gergen PJ, Szefler SJ, Mitchell HE, Calatroni A, Wildfire J, et al. Seasonal risk factors for asthma exacerbations among inner-city children. J Allergy Clin Immunol. 2015; 135(6): 1465-73. doi: 10.1016/j.jaci.2014.12.1942. PMID: 25794658, PMCID: PMC4461505.

21) Wheeler JG, Shema SJ, Bogle ML, Shirrell MA, Burks AW, Pittler A, et al. Immune and clinical impact of Lactobacillus acidophilus on asthma. Ann Allergy Asthma Immunol. 1997; 79(3): 229-33. PMID: 9305229.

22) Giovannini M, Agostoni C, Riva E, Salvini F, Ruscitto A, Zuccotti GV, et al. A randomized prospective double blind controlled trial on effects of long-term consumption of fermented milk containing Lactobacillus casei in pre-school children with allergic asthma and/or rhinitis. Pediatr Res. 2007; 62(2): 215-20. PMID: 17597643.

23) Gutkowski P, Madalinski K, Grek M, Dmenska H, Syczewska M, Michalkiewicz J. Effect of orally administered probiotic strains Lactobacillus and Bifidobacterium in children with atopic asthma. Centr Eur J Immunol. 2010; 35(4): 233-8.

24) Chapman CM, Gibson GR, Rowland I. In vitro evaluation of single- and multi-strain probiotics: Interspecies inhibition between probiotic strains, and inhibition of pathogens. Anaerobe. 2012; 18(4): 405-13. doi: 10.1016/j.anaerobe.2012.05.004. PMID: 22677262.

25) Das RR, Naik SS, Singh M. Probiotics as additives on therapy in allergic airway diseases: a systematic review of benefits and risks. Biomed Res Int. 2013; 2013: 231979. doi: 10.1155/2013/231979. PMID: 23956972, PMCID: PMC3727208.

26) Stockert K, Schneider B, Porenta G, Rath R, Nissel H, Eichler I. Laser acupuncture and probiotics in school age children with asthma: a randomized, placebo-controlled pilot study of therapy guided by principles of Traditional Chinese Medicine. Pediatr Allergy Immunol. 2007; 18(2): 160-6. PMID: 17338790.

27) Helin $T$, Haahtela $S$, Haahtela $T$. No effect of oral treatment with an intestinal bacterial strain, Lactobacillus rhamnosus (ATCC 53103), on birch-pollen allergy: a placebo-controlled double-blind study. Allergy. 2002; 57(3): 243-6. PMID: 11906339.

28) Rose MA, Stieglitz F, Koksal A, Schubert R, Schulze J, Zielen S. Efficacy of probiotic Lactobacillus GG on allergic sensitization and asthma in infants at risk. Clin Exp Allergy. 2010; 40(9): 1398-405. doi: 10.1111/j.1365-2222.2010.03560. PMID: 20604800.

29) Van der Aa LB, van Aalderen WM, Heymans HS, Henk Sillevis Smitt J, Nauta AJ, Knippels LM, et al. Synbiotics prevent asthma-like symptoms in infants with atopic dermatitis. Allergy. 2011; 66(2): 170-7. doi: 10.1111/j.1398-9995.2010.02416. PMID: 20560907. 